\title{
Speed control of SR motor by self-tuning fuzzy PI controller with artificial neural network
}

\author{
ERCUMENT KARAKAS ${ }^{1, *}$ and SONER VARDARBASI ${ }^{2}$ \\ ${ }^{1}$ Kocaeli University, Technical Education Faculty, Electrical Education \\ Department, Kocaeli, Turkey \\ ${ }^{2}$ Koprubasi Vocational School, Electrical Department, Trabzon, Turkey \\ *e-mail:karakas@kou.edu.tr
}

MS received 29 September 2006; revised 10 May 2007

\begin{abstract}
In this work, the dynamic model, flux-current-rotor position and torquecurrent-rotor position values of the switched reluctance motor (SRM) are obtained in MATLAB/Simulink. Motor control speed is achieved by self-tuning fuzzy PI (Proportional Integral) controller with artificial neural network tuning (NSTFPI). Performance of NSTFPI controller is compared with performance of fuzzy logic (FL) and fuzzy logic PI (FLPI) controllers in respect of rise time, settling time, overshoot and steady state error.
\end{abstract}

Keywords. Switched reluctance motor; fuzzy logic controller; artificial neural network; fuzzy logic PI controller; NSTFPI controller.

\section{Introduction}

The switched reluctance motor (SRM) is a doubly salient machine in which torque is produced by the tendency of the rotor to move to a position where the inductance of the excited windings is maximized. The simple mechanical construction is one of the main attractive features because it has no windings or permanent magnets on the rotor and thus, manufacturing cost appears to be lower compared to other motor types (Miller 2001). SRM has the advantages of simple structure, low cost and high efficiency. Along with those advantages SRM has a nonlinear magnetic structure and motor parameters are time varying. Because of these features, traditional controllers PI (Proportional Integral), PD (Proportional Derivative), PID (Proportional Integral Derivative) are insufficient in SRM control. Hence, non-linear controllers are needed in SRM control.

In SRM control, non-linear techniques such as sliding mode, artificial neural network (ANN), fuzzy logic and gain tuning PI controllers are used. Literature studies on switched reluctance motors and these controllers are as follows. Inanc. \& Ozbulur (2003) have used sliding mode control in SRM speed control. Ho et al (1998) have developed a gain tuning PI controller structure using the voltage applied on motor phase windings and motor rotor speed. Then they have used this structure on speed control. Instead of changing the parameters of the controller, Tandon et al (1997) aimed to operate the motor at the optimum point using an 
algorithm which changes the motor $\alpha$ and $\beta$ values in the system where they have used a PI controller. Chen et al (2002) have improved the motor dynamic performance and increased its efficiency by adjusting motor phase turn on and turn off values using fuzzy logic. Rodrigues et al (1997) have used fuzzy logic controller in speed control. Akcayol (2004) has used the adaptive neuro-fuzzy controller adjusting the membership functions of the fuzzy logic controller by employing artificial neural network. Paramasiwam \& Arumugan (2005) have used a hybrid controller consisting of PI and FLPI controllers and they have compared the performance of this controller with those of PI, FLPI and FLPD controller, in respect of steady state error. Husain \& Hossain (2005) have presented the modelling, simulation and control aspects of four-quadrant switched reluctance motor (SRM) drives. A complex model is described for the physical motor simulation to incorporate the important dynamics of SRM. Miller (2002) has made a few generic observations on the characteristics of successful products that use switched reluctance motors. Kjaer et al (1997) has formulated the objectives associated with high-grade torque control of switched reluctance motors (SRM's). A systematic approach to wave forms design has been developed and evaluated using both simulation and experimental testing of an SRM servo-drive system. Cheok \& Wang (2005) have described a novel angle estimation scheme for a real time digital signal processor (DSP) based switched reluctance motor drive using fuzzy logic where several unique techniques are implemented to improve the estimation accuracy. Sahoo et al (2005) have proposed the use of iterative learning control (ILC) in designing a torque controller for switched reluctance motors (SRMs). Kioskeridis \& Mademlis (2005) have investigated the problem of choosing the firing angles for accomplishing maximum efficiency in single-pulse controlled switched reluctance motor drives. Yan et al (2005) have utilized synthetically non-linear calculation, finite element method and magnetic circuit method to design prototype SRM and to realize an approach of control strategy. Sun et al (2005) have presented a new non-linear modelling method of bearingless SRM using finite element method (FEM) and artificial neural network (ANN). Xia et al (2006) have presented an approach of adaptive PWM speed control for switched reluctance motors (SRM) based on neural network. Hudson et al (2004) have performed simulation and analysis, have derived and demonstrated that a minimal neural network configuration is attainable to implement rotor position estimation in SRM drives.

In this work the objective is achieving SRM speed control in MATLAB/Simulink by selftuning fuzzy PI controller with ANN tuning. For this purpose, the dynamic model of a $5 \mathrm{Hp}$ motor is obtained using flux-current-rotor position and torque-current-rotor position values obtained by finite element analysis. Using this model performance of the controller is compared with the performances of NSTFPI, FL and FLPI controllers in respect of rise time, overshoot and steady state error.

\section{The dynamic characteristic of SRM}

The dynamic characteristics of SRM consist of its electromagnetic, torque and mechanical equations (Miller 2001).

\subsection{Electromagnetic equations}

If the mutual effect of the phases is neglected, the voltage applied to one phase of SRM can be expressed as follows.

$$
v_{j}=R_{j} \cdot i_{j}+\frac{d \lambda_{j}}{d t} j=1, \ldots, m
$$


here $v_{j}$ indicates the voltage applied on the phase windings, $i_{j}$ represents the phase current, $R_{j}$ shows the phase resistance and $\lambda_{j}$ is the phase current while $\mathrm{m}$ is the motor phase number. In the SRM, flux is a function of both the current and the rotor position. Accordingly equation (1) can be re-organized:

$$
v_{j}=R_{j} \cdot i_{j}+\frac{\partial \lambda_{j}}{\partial i_{j}} \cdot \frac{d i_{j}}{d t}+\frac{\partial \lambda_{j}}{\partial \theta_{j}} \cdot \frac{d \theta_{j}}{d t}
$$

here $\theta_{j}$ is the rotor position. When equation is re-arranged, phase current can be expressed as follows:

$$
\frac{d i_{j}}{d t}=\left(\frac{\partial \lambda_{j}}{\partial i_{j}}\right)^{-1} \cdot\left(v_{j}-R_{j} \cdot i_{j}-\frac{\partial \lambda_{j}}{\partial \theta_{j}} \cdot \frac{d \theta_{j}}{d t}\right)
$$

\subsection{Torque equations}

When each phase of the SRM is excited, it produces an instantaneous torque. When the instantaneous torques produced by the phases are added, the total torque induced in the motor is found. The instantaneous torque produced by one phase of the motor is as follows:

$$
T_{j}=\frac{\partial W_{c_{j}}\left(i_{j}, \theta_{j}\right)}{\partial \theta_{j}} \mid i_{j}=\text { constant }
$$

here $W_{c j}$ is the co-energy. Co-energy can be written as follows:

$$
W_{c j}=\int_{0}^{i_{j}} \lambda_{j}\left(i_{j}, \theta_{j}\right) \cdot d i_{j} \mid \theta_{j}=\mathrm{constant}
$$

If equation (5) is substituted in equation (4) the instantaneous torque of one phase can be re-arranged as below.

$$
T_{j}=\int_{0}^{i_{j}} \frac{\partial \lambda_{j}\left(i_{j}, \theta_{j}\right)}{\partial \theta_{j}} \cdot d i
$$

The total torque of the motor can be found by adding the instantaneous torques of the phases. The total torque $T_{e}$ of the motor can be written as:

$$
T_{e}=\sum_{j=1}^{m} T_{j}\left(i_{j}, \theta_{j}\right)
$$

\subsection{Mechanical equations}

Mechanical equations can be expressed as below:

$$
T_{e}-T_{l}=j \cdot \frac{d \omega_{r}}{d t}+B \cdot \omega_{r}
$$

here $T_{l}$ is the load torque, $\omega_{r}$ is the rotor speed, $j$ and $B$ are respectively the moment of inertia and the coefficient of friction. When equation (8) is re-arranged in order to write the speed expression,

$$
\frac{d \omega}{d t}=\frac{1}{j} \cdot\left[T_{e}-T_{l}-B \cdot \omega_{r}\right]
$$

will be found. 


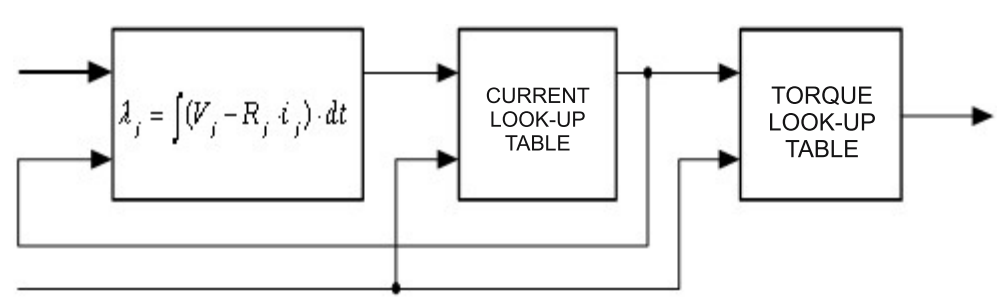

Figure 1. The electrical model of one phase of SRM.

\section{Dynamic model of SRM}

In this work the dynamic model of the SRM is derived using flux-current-rotor position and torque-current-rotor position data obtained by a finite element analysis.

In the dynamic model obtained, in order to estimate the phase current and phase torque when the input voltage and rotor position are known, current look-up table and torque lookup table are used. The current look-up table and the torque look-up table are formed using the flux-current-rotor position and the torque-current-rotor position data, respectively. In order to obtain the flux which is the input of the current look-up table equation (1) (Miller 2001) is re-arranged and used in the model. If equation (1) is re-arranged,

$$
\lambda_{j}=\int\left(v_{j}-R_{j} \cdot i_{j}\right) \cdot d t
$$

is obtained.

In equation (10), the current look-up table and the torque look-up table are combined and the electrical model of one phase is obtained in figure 1 . The electrical model of one phase of SRM is given.

When the electrical models of all phases are combined, the electrical model and the mechanical model are combined; the dynamical model of SRM seen in figure 2 is formed.

\section{Speed control of SRM}

In figure 3, the block diagram of the speed control of SRM is seen. The output of the speed controller is, the reference current, $i^{*}$. In this paper, the NSTFPI controller with ANN tuning

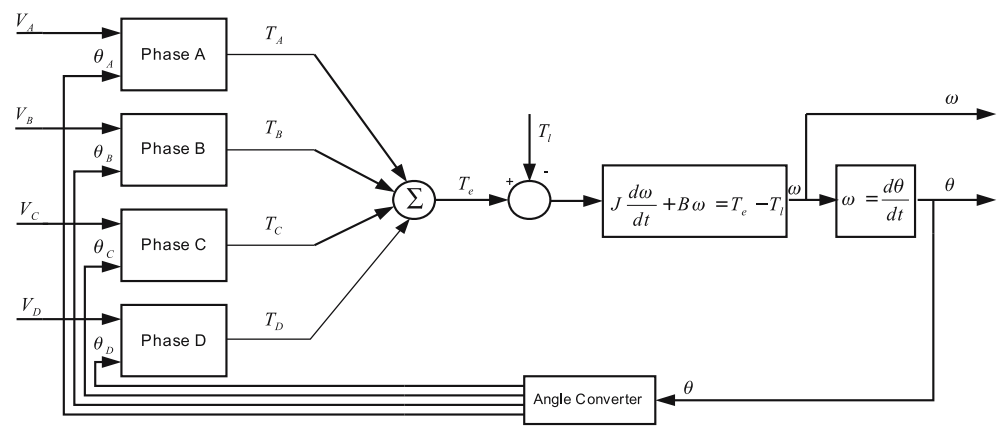

Figure 2. The dynamic model of the SRM. 


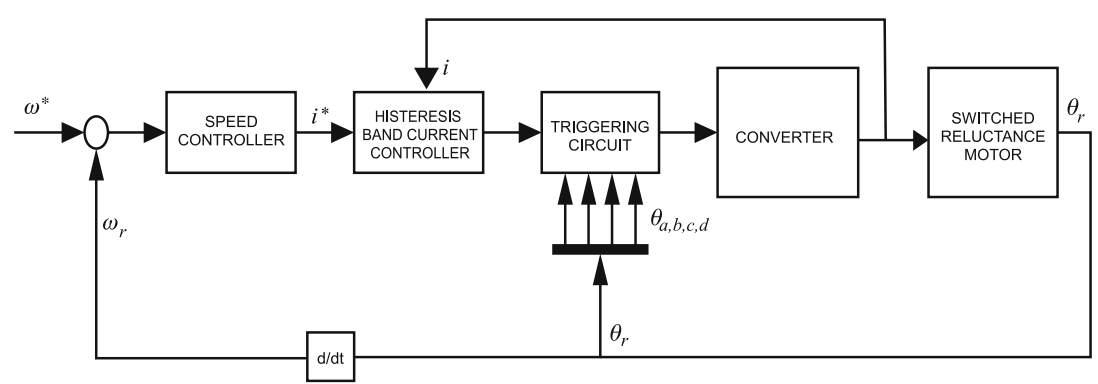

Figure 3. Speed control block diagram of SRM.

is used as the speed controller. The system also consists of a hysteresis band controller which does current control, a converter and a trigger circuit which drives the switches in the converter into conduction or cut off.

\section{Application of NSTFPI Controller}

The NSTFPI controller with ANN tuning used as the controller in the speed control of SRM is seen in figure 4. The NSTFPI controller consists of two parts; the FLPI and the selftuning mechanism. The purpose of self-tuning is to increase the controller performance by improving $\Delta i^{*}(k)$, the output of the controller. For this aim ANN is used as the self-tuning mechanism.

The NSTFPI controller has two input variables and one output variable. The input variables are $E(k)$ and $C E(k)$, while the output variable is $\Delta i^{*}(k)$.

The input and output variables of NSTFPI controller can be defined as

$$
\begin{aligned}
E(k) & =e(k) \cdot G_{e} \\
C E(k) & =c e(k) \cdot G_{c e} \\
\Delta i^{*}(k) & =\Delta I(k) \cdot G_{\Delta i} \cdot \alpha
\end{aligned}
$$

where $e(k)$ is the error between reference speed and rotor speed, $c e(k)$ is the change of error in speed, $\Delta I(k)$ is the output of the fuzzy logic controller, and $G_{e}, G_{c e}$ and $G_{\Delta i}$ are scaling factors.

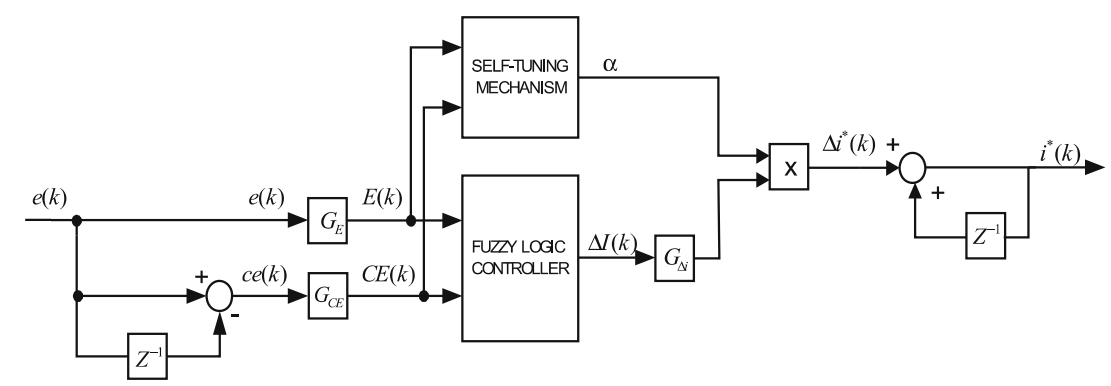

Figure 4. The structure of NSTFPI controller. 


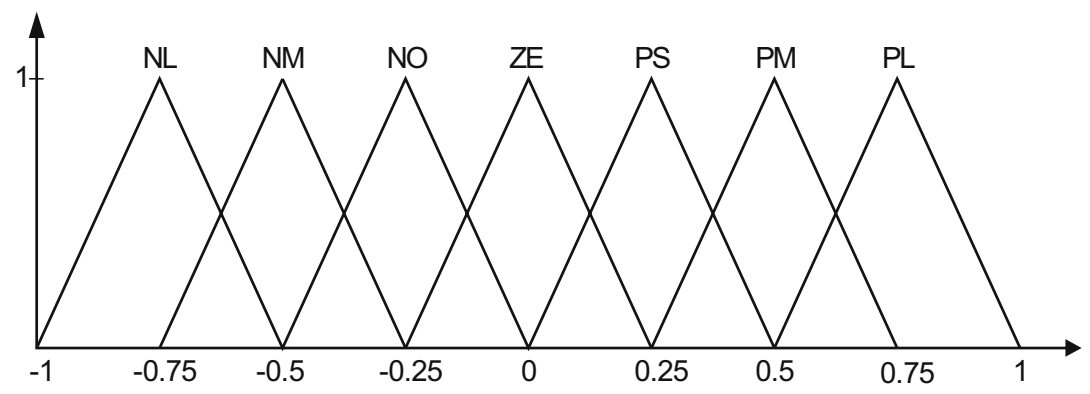

Figure 5. Membership functions of NSTFPI controller.

Figure 5 indicates the membership functions are triangle ones having linguistic labels of NL (Negative Large), NM (Negative Medium), NS (Negative Small), ZE (Zero), PS (Positive Small), PM (Positive Medium) and PL (Positive Large).

Table 1 shows the rule base of NSTFPI controller. The rule base consists of 49 IF-THEN rules.

The ANN used for self-tuning is feed forward with four layers. The structure of ANN is shown in figure 6.

\section{The comparison of speed results}

\subsection{No-load condition}

The system was operated at a reference speed of $157 \mathrm{rad} / \mathrm{s}$ when the motor shaft is under no load. The speed graphs obtained are shown in figure 7. The performance of NSTFPI, FLPI and FL controllers in terms of the rise time $\left(t_{r 0}\right)$, settling time $\left(t_{s 0}\right)$, overshoot $\left(O_{s}\right)$ and steady state error $\left(e_{s s}\right)$ are shown in table 2.

Table 1. The rules of FLPI controller.

\begin{tabular}{|c|c|c|c|c|c|c|c|c|}
\hline & \multicolumn{7}{|c|}{$E(k)$} \\
\hline & & NL & NM & NS & ZE & PS & PM & PL \\
\hline \multirow{7}{*}{ 竎 } & NL & NL & NL & NL & NM & NM & NS & ZE \\
\hline & NM & NL & NL & NM & NS & NS & $Z E$ & PS \\
\hline & NS & NL & NM & NS & NS & $Z E$ & PS & PM \\
\hline & $Z E$ & NM & NS & NS & ZE & PS & PS & PM \\
\hline & PS & NM & NS & $Z E$ & PS & PS & PM & PL \\
\hline & PM & NS & ZE & PS & PS & PM & PL & PL \\
\hline & PL & ZE & PS & PM & PM & PL & PL & PL \\
\hline
\end{tabular}




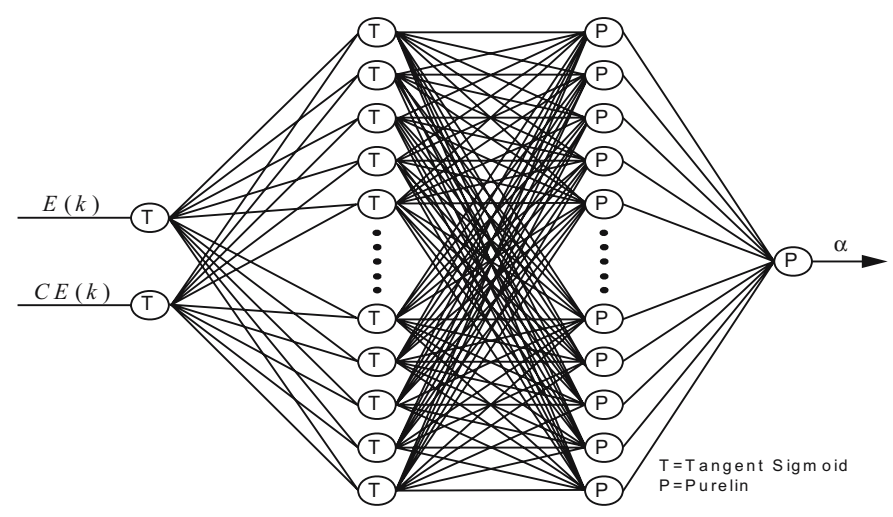

Figure 6. The structure of the feed forward ANN used for self-tuning $(2 \times 25 \times 15 \times 1)$.

\subsection{Load condition}

The system was operated after the motor was loaded with $10 \%(2 \cdot 3 \mathrm{Nm})$ of the nominal load. Figure 8 indicates speed responses at the reference speed of $157 \mathrm{rad} / \mathrm{s}$ under load condition. The performance of NSTFLPI, FLPI and FL controllers in terms of the rise time $\left(t_{r l}\right)$, settling time $\left(t_{s l}\right)$, overshoot $\left(O_{s}\right)$ and steady state error $\left(e_{s s}\right)$ under load condition are shown in table 3 .

\section{Conclusion}

When the studies done so far are reviewed, many studies which tend to increase performance of switched reluctance motor (SRM) are seen. It is found that basically two methods are used to increase performance of SRM in the literature. The first method is based on the design of the switched reluctance motors' magnetic circuit, and the second one is based on control circuit of the switched reluctance motors. With the second method, the artificial neural network control

Table 2. The performance analysis of NSTFPI, FLPI and FL controllers under no-load condition.

\begin{tabular}{lcccc}
\hline Controllers & $t_{r o}(\mathrm{~s})$ & $t_{s o}(\mathrm{~s})$ & $O_{s}(\mathrm{rad} / \mathrm{s})$ & $e_{s s}(\mathrm{rad} / \mathrm{s})$ \\
\hline NSTFPI & 0.1140 & 0.1140 & No overshoot & 0.021 \\
FLPI & 0.2000 & 0.2000 & No overshoot & 0.025 \\
FL & 0.2230 & 0.2230 & No overshoot & 0.028 \\
\hline
\end{tabular}

Table 3. The performance analysis of NSTFPI, FLPI and FL controllers under load condition.

\begin{tabular}{lcccc}
\hline Controllers & $t_{r l}(\mathrm{~s})$ & $t_{s l}(\mathrm{~s})$ & $O_{s}(\mathrm{rad} / \mathrm{s})$ & $e_{s s}(\mathrm{rad} / \mathrm{s})$ \\
\hline NSTFPI & $0 \cdot 1050$ & $0 \cdot 1050$ & No overshoot & 0.048 \\
FLPI & $0 \cdot 2015$ & 0.2015 & No overshoot & 0.065 \\
FL & $0 \cdot 3000$ & 0.3000 & No overshoot & 0.200 \\
\hline
\end{tabular}




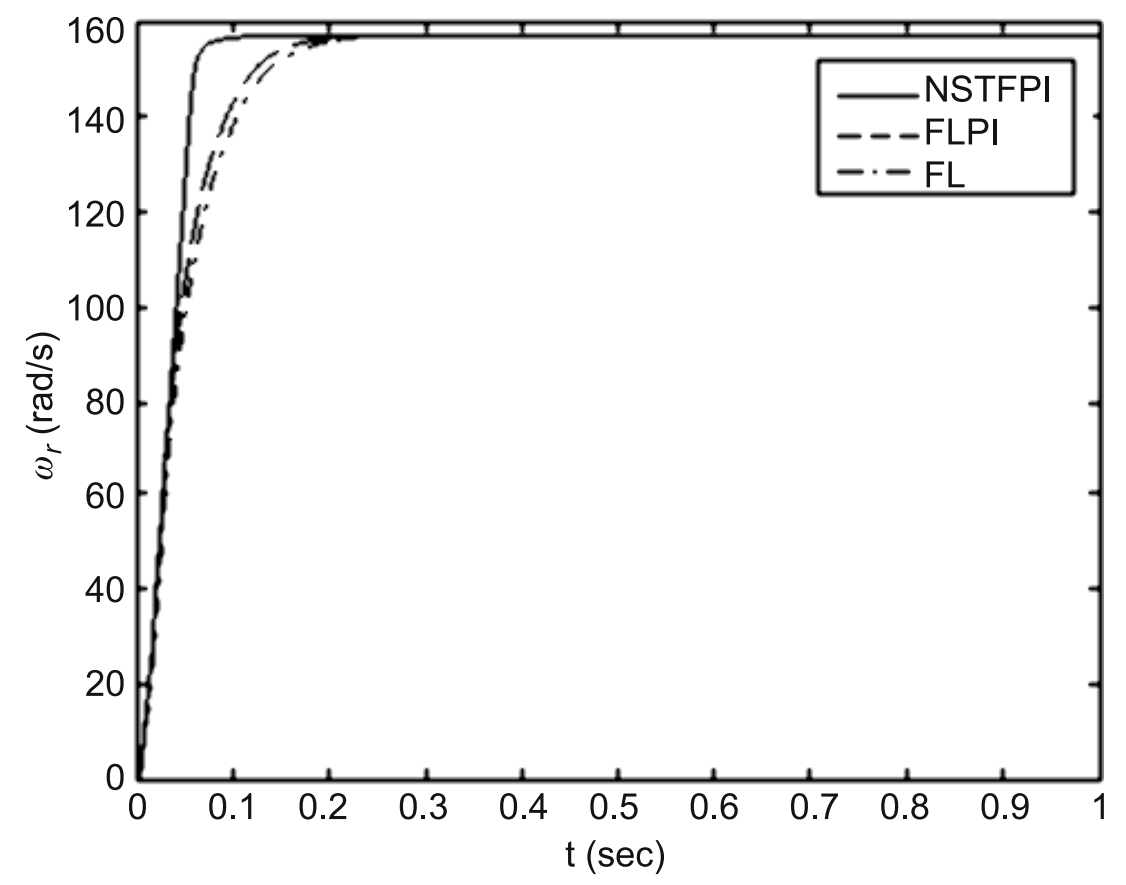

Figure 7. The speed responses of SRM using NSTFPI, FLPI, FL controllers under no-load condition.

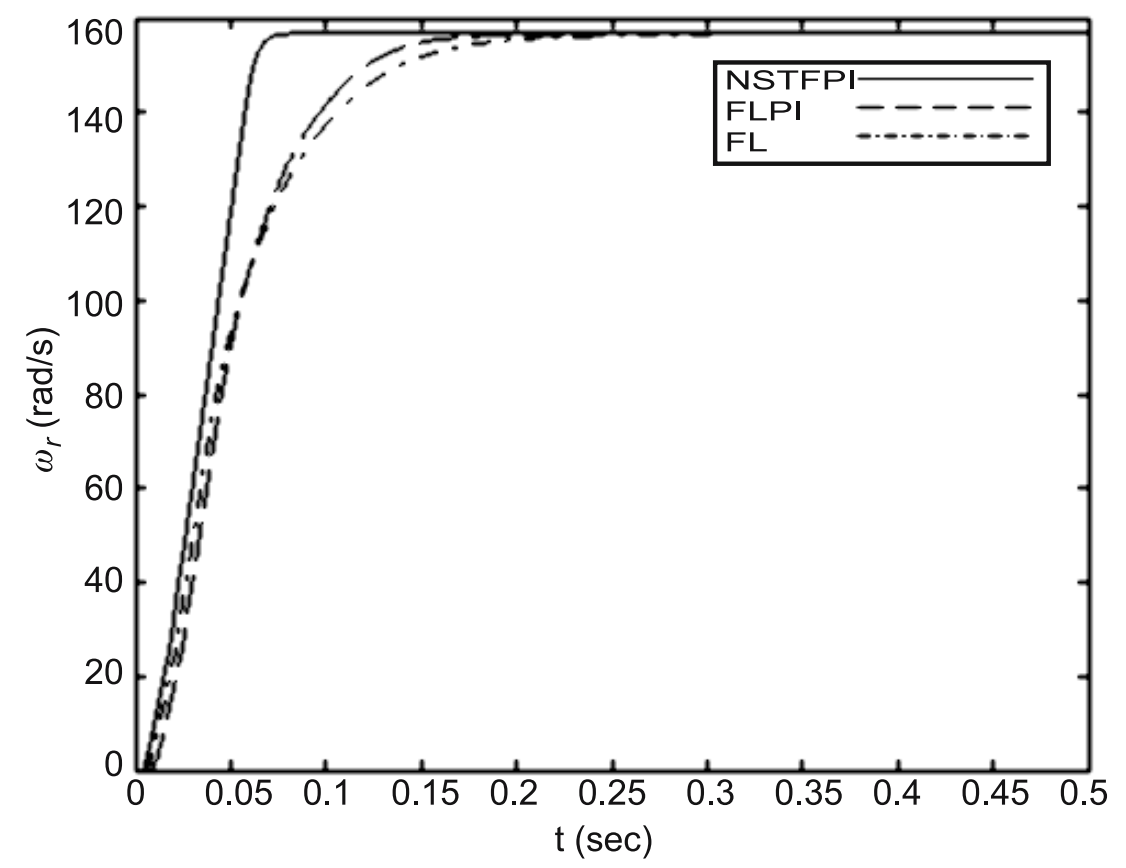

Figure 8. The speed responses of SRM with NSTFPI, FLPI and FL controllers under load condition. 
is used to control speed of the motor. From this point it is aimed to design NSTFPI to control speed of SRM and to increase control performance of the motor.

The processes performed for this purpose are listed below.

- Using finite element analysis method, flux-current-rotor and torque-current-rotor position values of a $5 \mathrm{Hp}$ SRM are obtained. The dynamic model of the motor is derived with the aid of these values.

- It is determined which control method gives a better performance for the SRM speed control in terms of rise time, settling time, overshoot and steady state error by using NSTFPI, FLPI and FL controllers.

- The performance of the controllers are evaluated under no-load and load conditions.

When the controller performances are examined under these conditions, the following results are obtained.

The performances of NSTFPI controller with ANN self-tuning and FLPI controller are almost the same in terms of overshoot and steady state error. However, the NSTFPI controller with ANN self-tuning is superior over FLPI in terms of rise time by $49.7 \%$ and $44.5 \%$ under no-load and load conditions, respectively. The results suggest that the NSTFPI controller with ANN tuning can be employed in the applications where the response time is important.

\section{References}

Akcayol M A 2004 Application of adaptive neuro-fuzzy controller for SRM. Advances in Engineering Software 35: 129-137

Chen H, Zhang D, Cong Z-Y, Zhang Z-F 2002 Fuzzy logic control for switched reluctance motor drive. Proc. of the $1^{\text {st }}$ Int. Confer. on Machine Learning and Cybernetic, Beijing, 145-149

Cheok A D, Wang Z 2005 Fuzzy logic rotor position estimation based switched reluctance motor DSP drive with accuracy enhancement. IEEE Trans. on Power Electronics 20: 908-921

Ho W K, Panda S K, Lim K W, Huang F S 1998 Gain-scheduling control of the switched reluctance motor. Control Eng. Practice 6: 181-189

Hudson C, Lobo N S, Krishnan R 2004 Sensorless control of single switched based switched reluctance motor drive using neural network. The $30^{\text {th }}$ Annual Conference of The IEEE Industrial Electronics Society, Korea, 2349-2354

Husain I, Hossain S A 2005 Modelling, simulation, and control of switched reluctance motor drives. IEEE Trans. on Ind. Electronics 52: 1625-1634

Inanc N, Ozbulur V 2003 Torque ripple minimization of switched reluctance motor by using sliding mode control technique. Electric Power Systems Research 66: 241-251

Kioskeridis I, Mademlis C 2005 Maximum efficiency in single-pulse controlled switched reluctance motor drives. IEEE Trans. on Energy Conversion 20: 809-817

Kjaer P C, Gribble J J, Miller T J E 1997 High-grade control of switched reluctance machines. IEEE Trans. on Industry Appl. 33: 1585-1593

Miller T J E 2001 Electronic control of switched reluctance machines, Newnes Power Engineering Series (Oxford: Newnes Publisher)

Miller T J E 2002 Optimal design of switched reluctance motors. IEEE Trans. on Ind. Electronics 49: $15-27$

Paramasiwam S, Arumugam R 2005 Hybrid fuzzy controller for speed control of switched reluctance motor drives. Energy Conversion and Manag. 46: 1365-1378

Rodrigues M G, Suemitsu W I, Branco P, Dente J A, Rolim L G B 1997 Fuzzy logic control of a switched reluctance motor. IEEE Int. Symp. on Ind. Electronics (ISIE'97), Portugal, 527-531

Sahoo S K, Panda S K, Xu J-X 2005 Indirect torque control of switched reluctance motors using iterative learning control. IEEE Trans. on Power Electronics 20: 200-208 
Sun J, Zhan Q, Liu L 2005 Modelling and control of bearingless switched reluctance motor based on artificial neural network. IEEE Ind. Electronics Society $32^{\text {nd }}$ Annual Conference on IEEE (IECON 2005) 1638-1643

Tandon P, Velayutham A R, Ehsani M 1997 Self-tuning control of a switched reluctance motor drive with shafts position sensor. IEEE Trans. on Industry Appl. 33: 1002-1010

Xia C, Chen Z, Xue M 2006 Adaptive PWM speed control for switched reluctance motors based on RBF neural network. IEEE Proc. of the $6^{\text {th }}$ World Congress on Intelligent Control and Automation, China 8103-8107

Yan W, Tianming Y, Yu F, Guoguo L 2005 Intelligent control for torque ripple minimization of SRM. IEEE Proc. of the Eight International Conference on Electrical Machines and Systems (ICEMS 2005) 742-747 